\title{
Significant reduction in the density of premature ventricular complex with ß-blocker medication in fast rate-dependent premature ventricular complex
}

Yae Min Park ${ }^{1 \dagger}$, Chang Yun Kim ${ }^{2+}$, Jungduk Seo ${ }^{1}$, Albert Youngwoo Jang ${ }^{1}$, Mi Sook Cha ${ }^{1}$, Woong Chol Kang ${ }^{1}$, Seung Hwan Han ${ }^{1}$, Mi-Seung Shin ${ }^{1}$ and In Suck Choi ${ }^{\text {1* }}$

\begin{abstract}
Background: There is little data regarding types of idiopathic premature ventricular complex (PVC) according to heart rate dependence.

Methods: One hundred and sixty-eight patients with idiopathic PVC were enrolled in this study. Evaluation of the number of PVCs and total ventricular beats, and the density of PVC was done using $24 \mathrm{~h}$ Holter monitoring. Patients were divided into groups as having: fast rate-dependent (Group I), slow rate-dependent (Group II), and heart rateindependent PVC (Group III) based on the relationship between the number of hourly PVC and hourly heart rate. After B-blocker medication, $24 \mathrm{~h}$ Holter monitoring was repeated.

Results: Among the 168 subjects, 66 (39.3\%) patients were in Group I, 18 (10.7\%) in Group II, and 84 (50.0\%) in Group III. There were no significant differences in the baseline number of PVCs and total ventricular beats, and the density of PVC among the three groups. The number of PVCs was significantly reduced in patients with Group I $(14,030 \pm 11,463$ beats/day vs. $7401 \pm 10,464$ beats/day, $p<0.001$ ), and total ventricular beat was significantly reduced in patients with Group I (109,223 $\pm 17,564$ beats/day vs. 96,182 $\pm 15,594$ beats/day, $p<0.001)$ and Group III $(106,515 \pm 13,468$ beats/ day vs. $97,995 \pm 12,960$ beats/day, $p<0.001)$ after B-blocker medication. The density of PVC was significantly reduced only in patients of Group I ( $12.9 \pm 10.3 \%$ vs. $7.4 \pm 10.3 \%, p=0.001)$ after $\beta$-blocker medication.
\end{abstract}

Conclusions: The type of PVC according to the heart rate dependence should be considered when treating idiopathic PVC with ß-blockers.

Keywords: Premature ventricular complex, Heart rate dependence, ß-blocker

\section{Introduction}

Premature ventricular complexes (PVCs) are common arrhythmias in clinical practice [1, 2]. Many patients with PVCs are asymptomatic, whereas some PVCs can

\footnotetext{
*Correspondence: ypruimin@gmail.com; ypruimin@naver.com

${ }^{\dagger}$ Yae Min Park and Chang Yun Kim have contributed equally to this work

${ }^{1}$ Division of Cardiology, Gil Medical Center, Gachon University, 774-21 Namdong Daero, Namdonggu, Incheon 21556, Republic of Korea

Full list of author information is available at the end of the article
}

cause symptoms of palpitations such as heart pounding, irregular, skipped, or paused heartbeat, or more generalized symptoms such as dizziness, near-syncope, dyspnea, chest pain, or fatigue [3]. It is usually a benign condition in a structurally normal heart; however, it may sometimes be considered a sign of increased risk of cardiomyopathy, left ventricular dysfunction, ischemic heart disease, and morbidity and mortality of cardiovascular disease and sudden death in patients with underlying structural heart disease $[1,4]$.

c) The Author(s) 2020. This article is licensed under a Creative Commons Attribution 4.0 International License, which permits use, sharing, adaptation, distribution and reproduction in any medium or format, as long as you give appropriate credit to the original author(s) and the source, provide a link to the Creative Commons licence, and indicate if changes were made. The images or other third party material in this article are included in the article's Creative Commons licence, unless indicated otherwise in a credit line to the material. If material is not included in the article's Creative Commons licence and your intended use is not permitted by statutory regulation or exceeds the permitted use, you will need to obtain permission directly from the copyright holder. To view a copy of this licence, visit http://creativeco mmons.org/licenses/by/4.0/. 

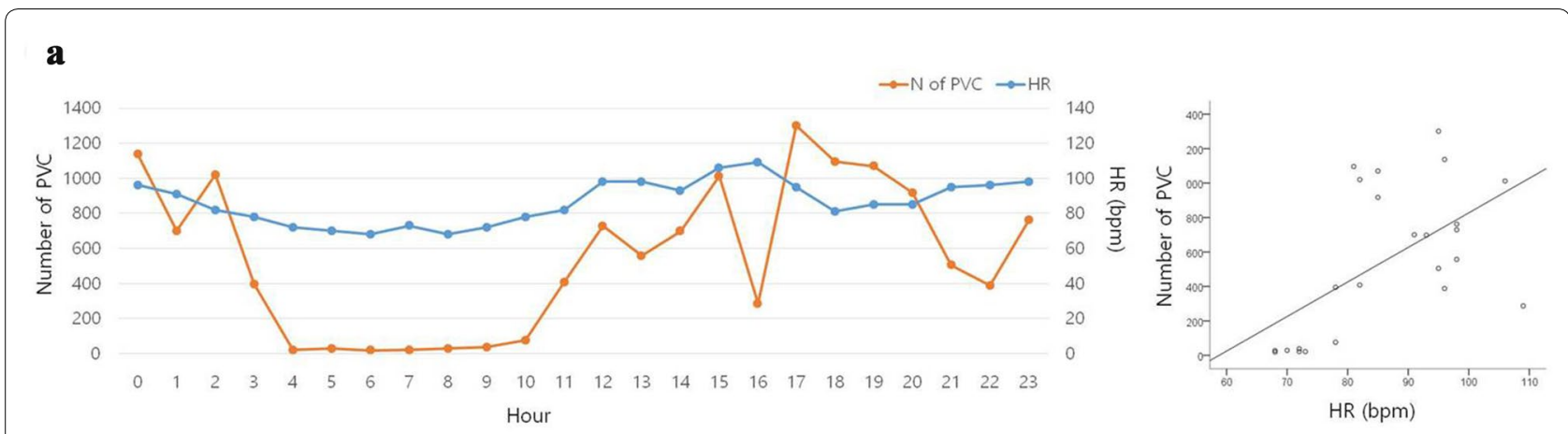

\section{b}
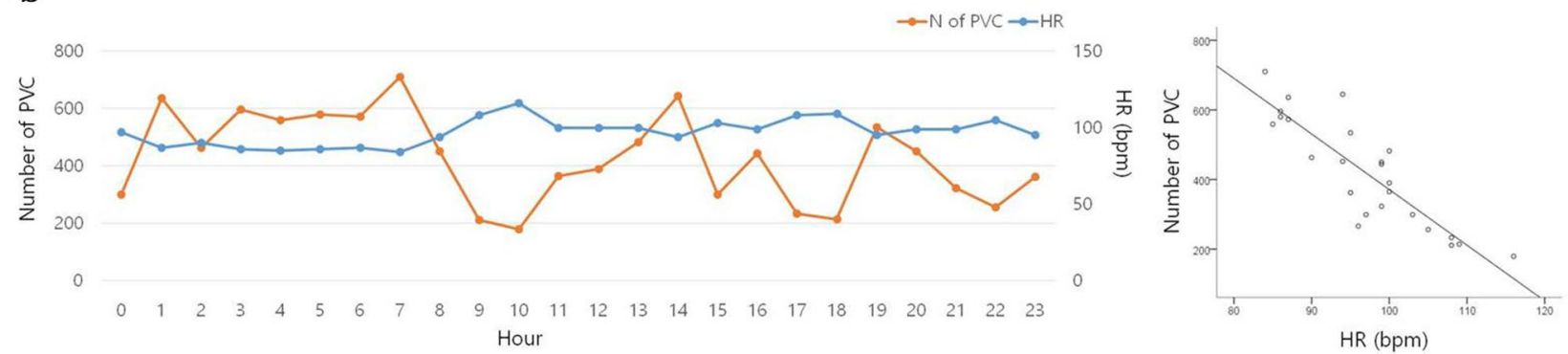

Fig. 1 Representative examples of fast rate-dependent PVC (Group I) and slow rate-dependent PVC (Group II) are shown

ß-blockers are the first-line medical therapy for symptomatic patients with PVC [5]. However, these drugs are effective only in some of the idiopathic PVC patients, suggesting that a different mechanism may exist in the pathogenesis of PVC.

This study evaluated: (1) the clinical characteristics of idiopathic PVC according to heart rate dependence; and (2) the changes in the PVC burden after intake of $\beta$-blocker medication according to the heart rate dependence.

\section{Patients and methods \\ Patients}

This is a retrospective study, and 168 patients who were diagnosed with idiopathic PVC between March 2013 and February 2017 were included in this study. Inclusion criteria consisted of patients having idiopathic PVC with the burden $>1 \%$ per day, as assessed by $24 \mathrm{~h}$ Holter monitoring. Exclusion criteria included patients with the following: (1) sustained ventricular tachycardia (VT) or ventricular fibrillation, (2) any form of structural cardiovascular diseases, (3) left ventricular ejection fraction (LVEF) $<50 \%$, (4) thyroid disorder, (5) liver or kidney disease, and (6) electrolyte abnormalities. None of the patients was taking anti-arrhythmic drugs or ß-blockers before enrollment, and patients who were prescribed anti-arrhythmic drugs were excluded. The study was approved by the local ethics committee.

\section{Electrocardiography and $24 \mathrm{~h}$ Holter monitoring}

Twelve-lead electrocardiography (ECG) was performed to evaluate the presence of PVC, and $24 \mathrm{~h}$ Holter monitoring was performed in all included patients at baseline. Patients were instructed to maintain their normal everyday activities but avoid intense physical exercise during the recordings. Number of PVCs was calculated, and number of total ventricular beats was defined as all the ventricular beats including sinus rhythm, PVCs and nonsustained VT. The density of PVC was defined as the percentage of PVC of total beats (\% of the number of PVC/ the number of total ventricular beats). Non-sustained VT was defined as three or more beats in duration terminating spontaneously within $30 \mathrm{~s}$ [6]. ß-blockers were prescribed for all patients except who are in contraindications, and $24 \mathrm{~h}$ Holter monitoring was followed-up after 3 months. The changes in the number of PVC and total ventricular beats, and the density of PVC were evaluated. 
Table 1 Baseline characteristics according to groups

\begin{tabular}{|c|c|c|c|c|}
\hline & Group I $(n=66)$ & Group II $(n=18)$ & Group III $(n=84)$ & $p$ value \\
\hline Age (years) & $51.7 \pm 17.3$ & $43.1 \pm 14.2$ & $49.7 \pm 13.4$ & 0.10 \\
\hline Sex, $n(\%)$ & $20(30.3)$ & $3(16.7)$ & $31(36.9)$ & 0.23 \\
\hline Smoking, $n(\%)$ & $10(15.2)$ & $3(16.7)$ & $10(11.9)$ & 0.79 \\
\hline Alcohol, $n(\%)$ & $18(27.3)$ & $6(33.3)$ & $26(31.0)$ & 0.83 \\
\hline HTN, $n(\%)$ & $17(25.8)$ & $4(22.2)$ & $18(21.4)$ & 0.82 \\
\hline $\mathrm{DM}, n(\%)$ & $3(4.5)$ & $2(11.1)$ & $6(7.1)$ & 0.58 \\
\hline CAD, $n(\%)$ & $1(1.5)$ & $0(0)$ & $0(0)$ & 0.46 \\
\hline Dyslipidemia, n (\%) & $30(45.5)$ & $8(44.4)$ & $39(46.4)$ & 0.99 \\
\hline LVEF (\%) & $61.7 \pm 11.5$ & $66.8 \pm 6.9$ & $61.5 \pm 8.4$ & 0.12 \\
\hline LA diameter (mm) & $38.8 \pm 7.2$ & $38.8 \pm 6.1$ & $37.7 \pm 6.8$ & 0.70 \\
\hline LA volume $(\mathrm{mL})$ & $44.2 \pm 15.2$ & $39.7 \pm 11.7$ & $53.6 \pm 75.1$ & 0.46 \\
\hline LA volume index $\left(\mathrm{mL} / \mathrm{m}^{2}\right)$ & $27.0 \pm 9.4$ & $23.0 \pm 6.8$ & $33.0 \pm 51.2$ & 0.48 \\
\hline$E(\mathrm{~cm} / \mathrm{s})$ & $0.70 \pm 0.21$ & $0.66 \pm 0.17$ & $0.66 \pm 0.20$ & 0.99 \\
\hline$A(\mathrm{~cm} / \mathrm{s})$ & $0.67 \pm 0.17$ & $0.58 \pm 0.19$ & $0.66 \pm 0.17$ & 0.22 \\
\hline$E^{\prime}(\mathrm{cm} / \mathrm{s})$ & $0.07 \pm 0.03$ & $0.08 \pm 0.03$ & $0.75 \pm 0.28$ & 0.55 \\
\hline$A^{\prime}(\mathrm{cm} / \mathrm{s})$ & $0.08 \pm 0.23$ & $0.08 \pm 0.02$ & $0.10 \pm 0.10$ & 0.41 \\
\hline$E / e^{\prime}$ & $10.77 \pm 5.68$ & $9.16 \pm 3.24$ & $9.68 \pm 3.63$ & 0.28 \\
\hline $\mathrm{Na}(\mathrm{mEq} / \mathrm{L})$ & $137 \pm 16$ & $139 \pm 2$ & $140 \pm 2$ & 0.45 \\
\hline$K(\mathrm{mEq} / \mathrm{L})$ & $4.3 \pm 0.4$ & $4.3 \pm 0.3$ & $4.9 \pm 4.7$ & 0.55 \\
\hline Cholesterol (mg/dL) & $181 \pm 37$ & $170 \pm 35$ & $186 \pm 42$ & 0.35 \\
\hline $\mathrm{BNP}(\mathrm{pg} / \mathrm{mL})$ & $56.8 \pm 46.8$ & $53.6 \pm 70.3$ & $37.2 \pm 46.8$ & 0.22 \\
\hline Free T4 (ng/dL) & $1.2 \pm 0.2$ & $1.2 \pm 0.2$ & $1.2 \pm 0.2$ & 0.89 \\
\hline $\mathrm{TSH}(\mu \mathrm{IU} / \mathrm{mL})$ & $2.2 \pm 1.6$ & $1.9 \pm 1.0$ & $1.8 \pm 1.7$ & 0.35 \\
\hline ß-blockers medications & & & & 0.24 \\
\hline Carvedilol & $12(19.1)$ & $3(21.4)$ & $9(12.3)$ & \\
\hline Bisoprolol & $29(46.0)$ & $5(35.7)$ & $34(46.6)$ & \\
\hline Nebivolol & $6(9.5)$ & $5(35.7)$ & $14(19.2)$ & \\
\hline Betaxolol & $16(25.4)$ & $1(7.1)$ & $15(20.5)$ & \\
\hline Bevantolol & 0 & 0 & $1(1.4)$ & \\
\hline
\end{tabular}

$B N P$ brain natriuretic peptide, $C A D$ coronary artery disease $D M$ diabetes mellitus, HTN hypertension, $L A$ left atrial, $L V E F$ left ventricular ejection fraction, $P V C$ premature ventricular complex, TSH thyroid stimulating hormone

Table 2 Baseline parameters of $24 \mathrm{~h}$ Holter monitoring according to groups

\begin{tabular}{|c|c|c|c|c|}
\hline & Group I $(n=66)$ & Group II $(n=18)$ & Group III $(n=84)$ & $p$ value \\
\hline PVC (beats/day) & $13,775 \pm 11,950$ & $10,457 \pm 11,463$ & $11,704 \pm 11,097$ & 0.41 \\
\hline Ventricular beat (beats/day) & $106,788 \pm 16,992$ & $109,124 \pm 13,119$ & $105,652 \pm 13,784$ & 0.66 \\
\hline PVC density (\%) & $12.8 \pm 10.8$ & $9.3 \pm 9.8$ & $10.8 \pm 9.7$ & 0.33 \\
\hline non-sustained VT, n (\%) & $14(21.2)$ & $2(11.8)$ & $18(12.4)$ & 0.65 \\
\hline Longest beat of non-sustained VT (beats) & $3.7 \pm 1.3$ & $3.0 \pm 0.0$ & $4.1 \pm 1.7$ & 0.59 \\
\hline
\end{tabular}

PVC premature ventricular complex, VT ventricular tachycardia

\section{Statistical analysis}

Continuous variables are reported as a mean \pm standard deviation, while categorical variables are reported as a number or percentage. One-way ANOVA was used to compare continuous variables, while categorical variables were compared using a Chi-square test or Fisher's exact test, as appropriate among groups. Hourly mean heart rate and the number of PVCs were evaluated, and patients were divided into three groups according to their association, which was analyzed by Pearson's correlation. If the coefficient of correlation $\geq 0.3$ with $p<0.05$ and PVC density was positively related to heart rate, 


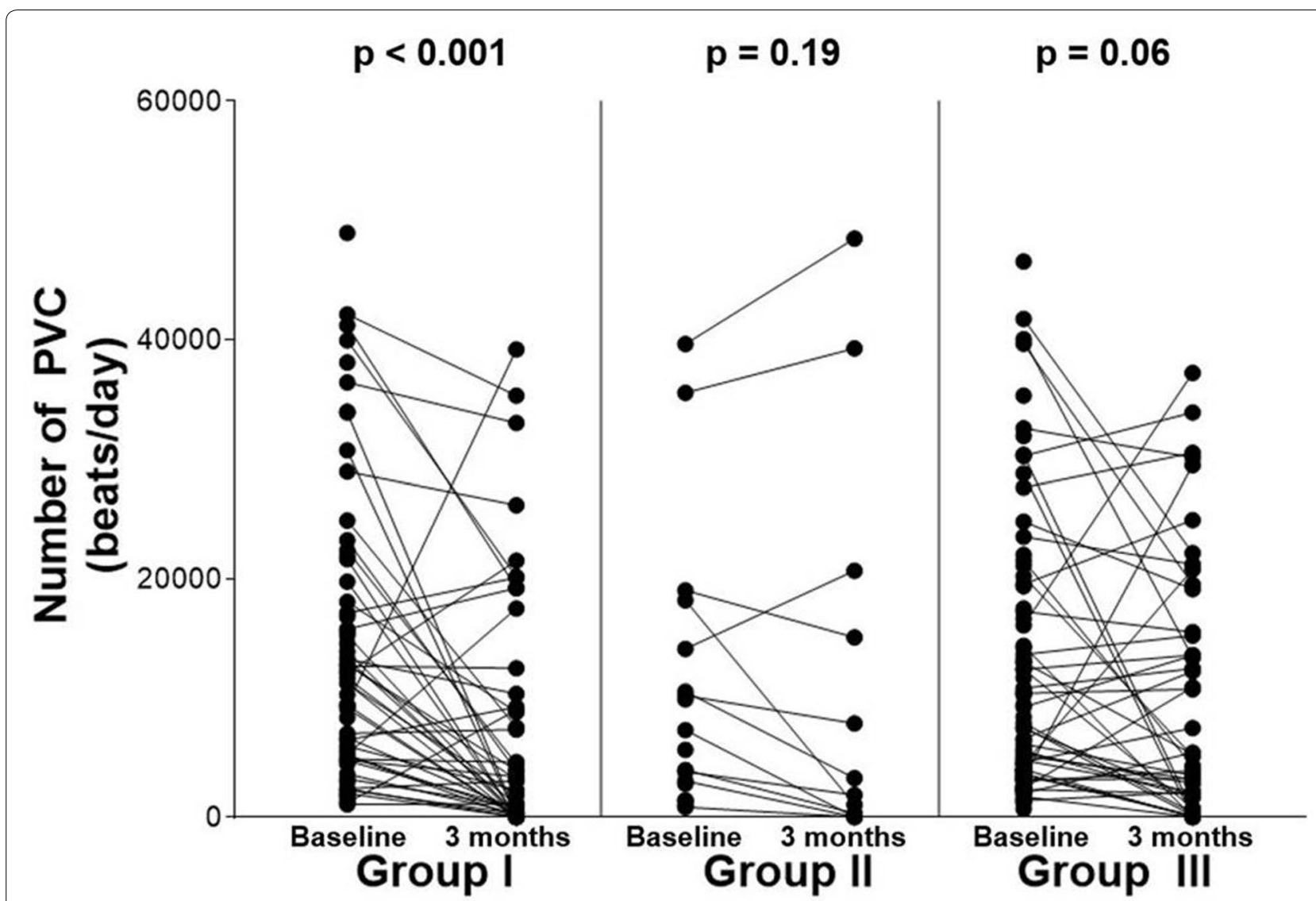

Fig. 2 Changes in the number of PVCs after $\beta$-blocker treatment according to groups. The density of the PVC was significantly reduced only in patients of Group I, and there were no significant differences in those of Group II and Group III. PVC = premature ventricular complex

these patients were defined as having fast rate-dependent PVC (Group I); and those with coefficient of correlation $\leq-0.3$ with $p<0.05$ and negatively related heart rate were defined as having slow rate-dependent PVC (Group II). No evident relationship between heart rate and PVC density was found in the rest of the patients $(-0.3<$ coefficient of correlation $<0.3$ ), and those PVCs were defined as heart rate-independent PVC (Group III). Representative examples of fast rate-dependent PVC (Group I) and slow rate-dependent PVC (Group II) are shown in Fig. 1. The changes in the number of PVCs and total ventricular beats and the density of PVC after 3 months of $B$-blocker medication were evaluated with repeated measure ANOVA test.

All statistical analyses were performed using SPSS 24.0 software (SPSS, Inc., an IBM Company, Chicago, Illinois, USA). Values of $p<0.05$ were considered significant. All tests were two-sided.

\section{Results}

\section{Baseline characteristics}

In total, 168 patients were included in the analysis. The mean age was $49.8 \pm 15.2$ years, and 54 patients (32.1\%) were male. Patients were divided into three groups according to the heart rate dependence; Group I $(n=66$, $39.3 \%)$, Group II $(n=18,10.7 \%)$, and Group III $(n=84$, $50.0 \%)$. Baseline characteristics among groups are compared in Table 1. There were no significant differences in age, sex, smoking, drinking, and the presence of cardiovascular comorbidities among the three groups. There were no significant differences in echocardiographic parameters including LVEF, left atrial size, and e/e' ratio. Twenty-eight patients (16.7\%) were asymptomatic, and there was no difference in the presence of the PVCrelated symptoms among groups.

\section{$24 \mathrm{~h}$ Holter monitoring}

Comparison of parameters of $24 \mathrm{~h}$ Holter monitoring among groups is presented in Table 2. There were no significant differences in the baseline number of PVCs and 


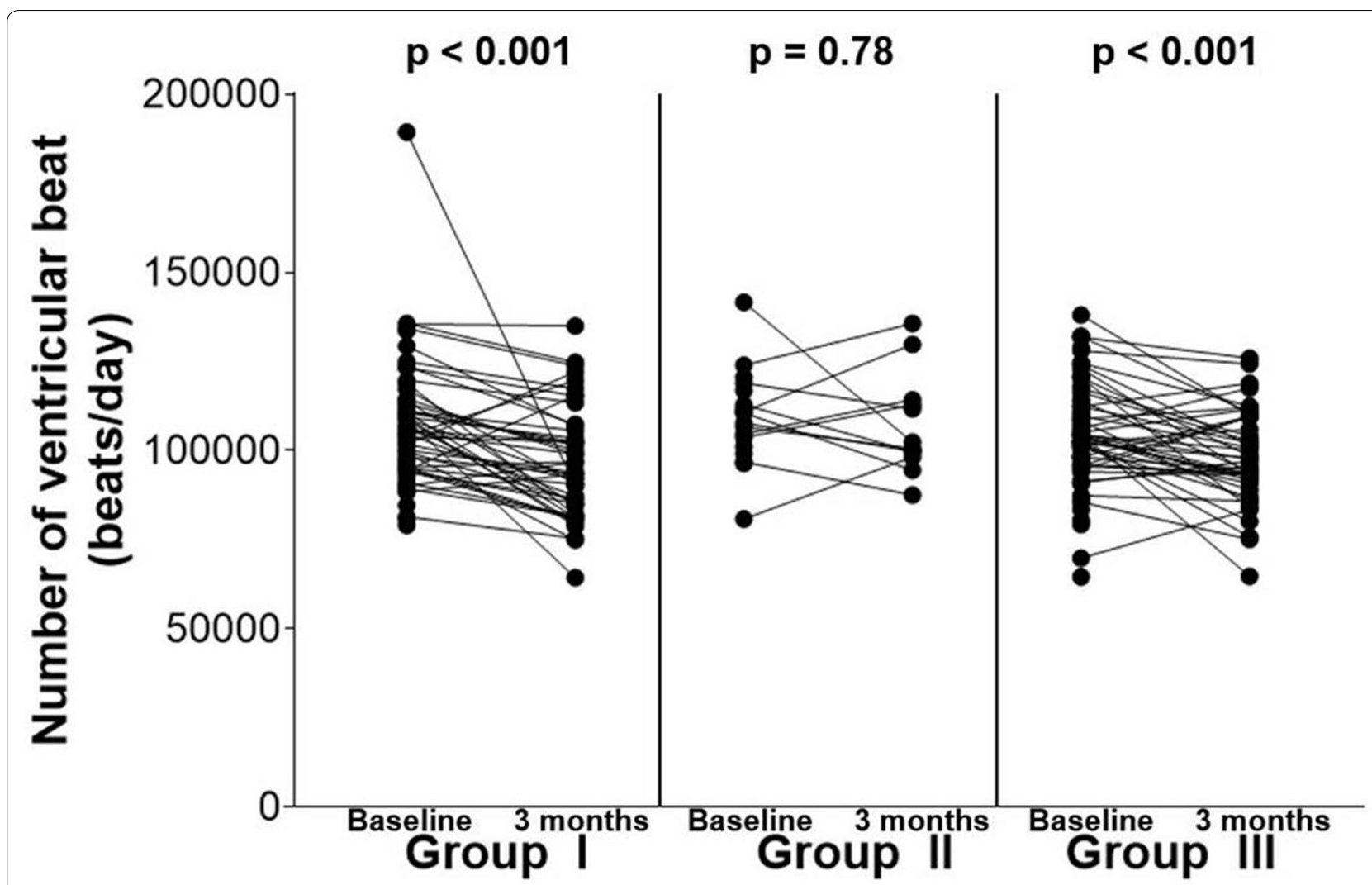

Fig. 3 Changes in the number total ventricular beats after $\beta$-blocker treatment according to groups. The number of total ventricular beats was significantly reduced in patients of Group I and Group III, whereas there was no significant change in patients of Group II

total ventricular beats, density of PVC, and the presence of non-sustained VT among the three groups.

\section{Effects of B-blockers}

The changes in the number of PVCs and total ventricular beats, and the density of PVC were evaluated after 3 months of $B$-blocker intake. The number of PVCs was significantly reduced in patients of Group I $(14,030 \pm 11,464$ beats/day vs. $7401 \pm 10,464$ beats/ day, $p<0.001)$ after $\beta$-blocker intake, whereas there were no significant changes in patients of Group II $(11,868 \pm 11,046$ beats/day vs. $8957 \pm 14,829$ beats/ day, $p=0.19)$ and Group III $(13,463 \pm 11,579$ beats/ day vs. $10,269 \pm 10,687$ beats/day, $p=0.06$ ) (Fig. 2). The number of total ventricular beats was significantly reduced in patients of Group I $(109,223 \pm 17,564$ beats/ day vs. $96,183 \pm 15,594$ beats/day, $p<0.001$ ) and Group III $(106,515 \pm 13,468$ beats/day vs. $97,995 \pm 12,960$ beats/day, $p<0.001)$, whereas there was no significant change in patients of Group II $(108,922 \pm 14,829$ beats/ day vs. $108,365 \pm 14,320$ beats/day, $p=0.78$ ) (Fig. 3). The density of the PVC was significantly reduced only in patients of Group I $(12.9 \pm 10.3 \%$ vs. $7.4 \pm 10.3 \%$, $p=0.001)$, and there were no significant differences in those of Group II $(10.4 \pm 9.1 \%$ vs. $7.3 \pm 11.1 \%, p=0.09)$ and Group III $(12.2 \pm 9.8 \%$ vs. $10.0 \pm 10.1 \%, p=0.15)$ (Fig. 4). We separated day and night in Group II and analyzed the changes in the number of PVCs and total ventricular beats, and the density of PVC, respectively. The ineffectiveness of $ß$-blocker in Group II was consistently shown in both daytime and nighttime.

\section{Discussion}

Patients with idiopathic PVC were categorized into three groups according to the heart rate dependence in the present study. We evaluated the differences in clinical characteristics and the changes in the PVC burden after B-blocker intake among the groups. Half of the patients belonged to Group III (heart rate-independent), and patients of Group II (slow rate-dependent PVC) accounted for the lowest number. The number of total ventricular beats was significantly reduced in patients of Group I and Group III; however, the number of PVCs and density of the PVC was significantly reduced only in patients of Group I. 


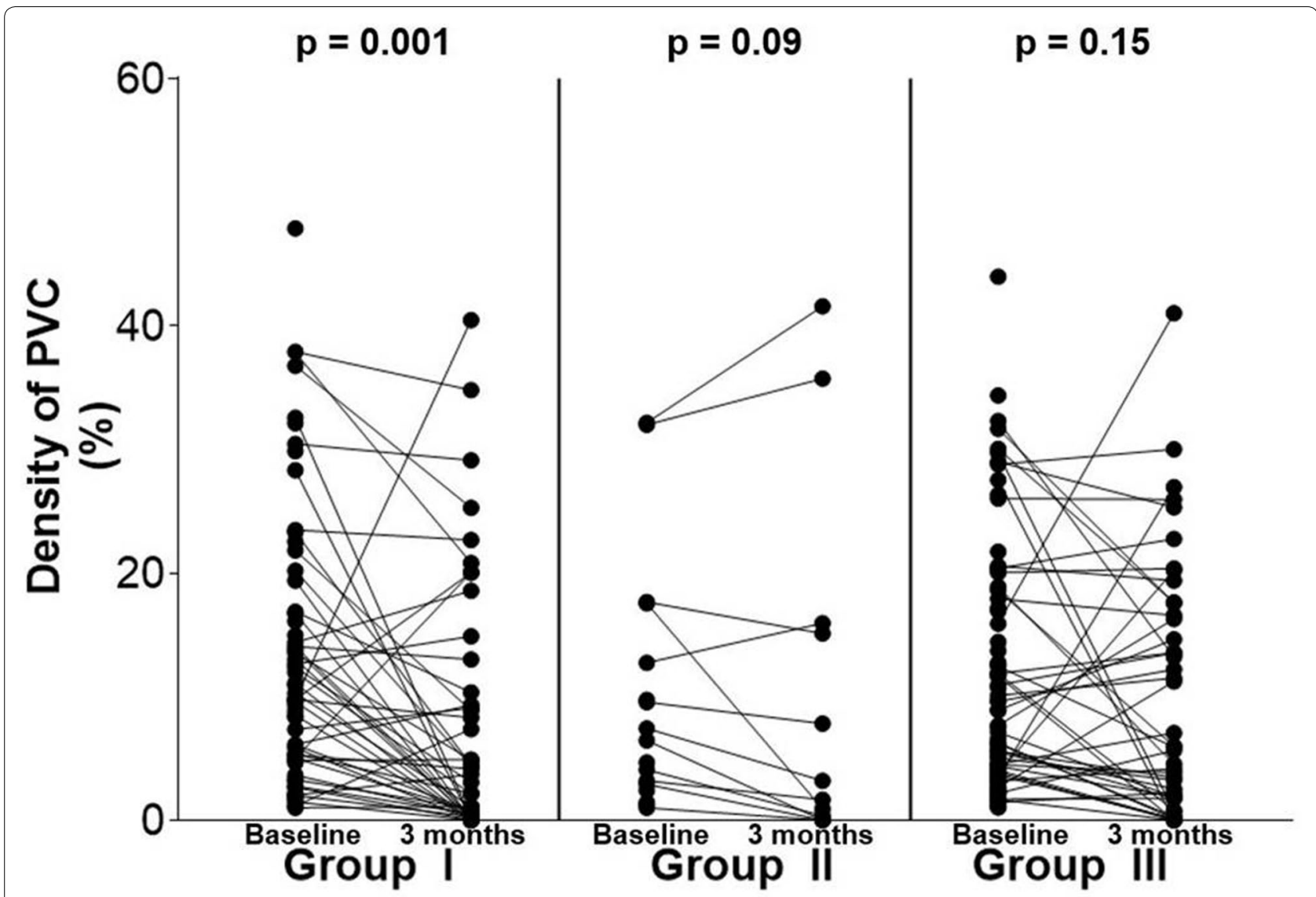

Fig. 4 Changes in the density of PVC after $\beta$-blocker treatment according to groups. The density of the PVC was significantly reduced only in patients of Group I and there were no significant differences in those of Group II and Group III. PVC= premature ventricular complex

Several data regarding the number of PVCs according to heart rate dependence have been published previously [7-9]. It is a consistent finding throughout studies that the slow-rate-dependent PVC accounts for the lowest percentage. However, the proportion of patients with heart rate-independent PVC is different among studies. We demonstrated that the substantial number of patients are categorized to the heart rate-independent group.

The mechanism of anti-arrhythmic efficacy of $B$-blockers involves competitive adrenergic-receptor blockade of sympathetically mediated triggering mechanisms, slowing of the sinus rate, and possible inhibition of excess calcium release by the ryanodine receptor [10]. We classified the patients into three groups according to heart rate dependence, and $\beta$-blocker was effective in reducing both frequency and density of PVC only in Group I. Similar results was shown in recent study which demonstrated that the transdermal bisoprolol patch was effective for a PVC reduction in patients with fast ratedependent PVC [11].

Heart rate and rhythm are regulated by the autonomic nervous system, and both parasympathetic and sympathetic nervous systems interact continuously [12]. Autonomic imbalance is a common pathophysiological pathway of many of these triggers. Both sympathetic overactivity and enhanced vagal control could contribute to ventricular arrhythmogenesis by complex electrophysiological mechanisms [5]. B-blockers significantly reduced the number of total ventricular beats per day in Group I and Group III, but not in Group II (slow rate-dependent PVC) in our study. This suggests that significant vagal activation might contribute to the pathogenesis of slow rate-dependent PVC. Recent studies on the differences in heart rate variability in patients with PVC according to heart rate dependence have been published. Hourly PVC density was positively associated with sympathetic indices in fast ratedependent PVC [7] and positively associated with vagal indices in slow rate-dependent PVC in these studies [7, 13]. Sympathetic nervous system activity, which was measured by the low frequency power/high frequency power ratio, was dominant in some PVCs [14], while vagally mediated parameters are enhanced in other PVCs [13]. Even though we did not include heart rate 
variability results, our findings support the previous data that showed that fast rate-dependent PVCs and slow rate-dependent PVCs might be facilitated by sympathetic activation and vagal activation, respectively.

After performing $24 \mathrm{~h}$ Holter monitoring, idiopathic PVCs may easily be categorized into three groups according to their HR dependency. In patients with slow ratedependent and heart rate-independent PVCs, ß-blockers have a minimal role to play and other anti-arrhythmic drugs may be considered as the next step to suppress the PVC burden with caution.

\section{Limitations}

There are several limitations in our study. We did not separate day and night when we analyzed the relationship between heart rate and PVC burden, which can affect a relatively high proportion of patients with heart rateindependent PVC (Group III) [15]. Spontaneous variability of ventricular ectopy in the day to day was reported $[16,17]$; therefore, we cannot conclude that the reduction in PVC density is the sole effect of $\beta$-blocker intake. We did not analyze the relationship with origin of PVC by the 12-lead ECG criteria and the morphology of PVC was not evaluated during follow-up. Detailed analysis regarding the dose of $\beta$-blockers was not performed because of the heterogeneity of the drug types. The number of patients with slow rate-dependent PVC (Group II) is relatively small in the present study.

\section{Conclusions}

The density of PVC was significantly reduced only in patients with fast rate-dependent PVC (Group I) after ß-blocker intake. The treatment response to $ß$-blockers can be predicted according to heart rate dependence. Further large scaled, prospective clinical studies associated with autonomic nervous system function are required.

\section{Abbreviations}

ECG: Electrocardiography; LVEF: Left ventricular ejection fraction; PVC: Premature ventricular complex.

\section{Acknowledgements}

Not applicable.

\section{Authors' contributions}

YMP, CYK and ISC conceived and designed the study. JS, AYJ and MSC performed data collection and analyses. WCK, SHH and ISC enrolled the subjects. YMP, WCK and SHH contributed to conceptualization of the study and conducting the study. SHH and MSS supervised data analysis and interpretation. YMP and CYK drafted the manuscript. ISC revised the article. All authors read and approved the final manuscript.

Funding

Not applicable.
Availability of supporting data Not applicable.

\section{Ethical Approval and Consent to participate}

This study was approved by the institutional review board of the Gachon University (No. GAIRB 2020-226). Informed consent was not obtained due to retrospective study design.

\section{Consent for publication \\ Not applicable.}

\section{Competing interests}

The authors declare that they have no competing interests.

\section{Author details}

${ }^{1}$ Division of Cardiology, Gil Medical Center, Gachon University, 774-21 Namdong Daero, Namdonggu, Incheon 21556, Republic of Korea. ${ }^{2}$ Pediatric Department, Gil Medical Center, Gachon University, Incheon, Korea.

Received: 14 September 2020 Accepted: 13 November 2020

Published online: 04 December 2020

\section{References}

1. Saurav A, Smer A, Abuzaid A, et al. Premature ventricular contractioninduced cardiomyopathy. Clin Cardiol. 2015;38:251-8.

2. Kostis JB, McCrone K, Moreyra AE, et al. Premature ventricular complexes in the absence of identifiable heart disease. Circulation. 1981;63:1351-6.

3. Kennedy HL, Whitlock JA, Sprague MK, et al. Long-term follow-up of asymptomatic healthy subjects with frequent and complex ventricular ectopy. N Engl J Med. 1985;312:193-7.

4. Gorenek B, Fisher JD, Kudaiberdieva G, et al. Premature ventricular complexes: diagnostic and therapeutic considerations in clinical practice: a state-of-the-art review by the American College of Cardiology Electrophysiology Council. J Interv Card Electrophysiol. 2020;57:5-26.

5. Shen MJ, Zipes DP. Role of the autonomic nervous system in modulating cardiac arrhythmias. Circ Res. 2014;114:1004-21.

6. Al-Khatib SM, Stevenson WG, Ackerman MJ, et al. 2017 AHA/ACC/HRS guideline for management of patients with ventricular arrhythmias and the prevention of sudden cardiac death: a report of the American College of Cardiology/American Heart Association Task Force on clinical practice guidelines and the heart rhythm society. J Am Coll Cardiol. 2018;72:e91-220.

7. He W, Lu Z, Bao M, et al. Autonomic involvement in idiopathic premature ventricular contractions. Clin Res Cardiol. 2013:102:361-70.

8. Inoue T, Koumatsu K, Ito M, et al. Heart rate-dependent alteration of the frequency and coupling interval of ventricular arrhythmias as measured by 24-hour ECG monitoring. Jpn Circ J. 1991;55:942-50.

9. Pitzalis M, Massari F, Totaro P, et al. Is it possible to predict the antiarrhythmic effect of beta blockers based on various relations between premature ventricular beat and the preceding cardiac cycle? Cardiologia. 1992;37:853-7.

10. Reiken $\mathrm{S}$, Wehrens $X \mathrm{H}$, Vest JA, et al. Beta-blockers restore calcium release channel function and improve cardiac muscle performance in human heart failure. Circulation. 2003;107:2459-66.

11. Shinohara $M$, Fujino $T$, Koike $H$, et al. Assessment of a novel transdermal selective beta1-blocker, the bisoprolol patch, for treating frequent premature ventricular contractions in patients without structural heart disease. J Cardiol. 2017;70:212-9.

12. Rajendra Acharya U, Paul Joseph K, Kannathal N, et al. Heart rate variability: a review. Med Biol Eng Comput. 2006;44:1031-51.

13. Frigy A, Csiki E, Carasca C, et al. Autonomic influences related to frequent ventricular premature beats in patients without structural heart disease. Medicine (Baltimore). 2018;97:e11489.

14. Barutcu A, Temiz A, Bekler A, et al. Arrhythmia risk assessment using heart rate variability parameters in patients with frequent ventricular ectopic beats without structural heart disease. Pacing Clin Electrophysiol. 2014;37:1448-54. 
15. Acanfora D, Pinna GD, Gheorghiade M, et al. Effect of beta-blockade on the premature ventricular beats/heart rate relation and heart rate variability in patients with coronary heart disease and severe ventricular arrhythmias. Am J Ther. 2000;7:229-36.

16. Michelson EL, Morganroth J. Spontaneous variability of complex ventricular arrhythmias detected by long-term electrocardiographic recording. Circulation. 1980;61:690-5.

17. Pratt CM, Theroux P, Slymen D, et al. Spontaneous variability of ventricular arrhythmias in patients at increased risk for sudden death after acute myocardial infarction: consecutive ambulatory electrocardiographic recordings of 88 patients. Am J Cardiol. 1987;59:278-83.

\section{Publisher's Note}

Springer Nature remains neutral with regard to jurisdictional claims in published maps and institutional affiliations.
Ready to submit your research? Choose BMC and benefit from:

- fast, convenient online submission

- thorough peer review by experienced researchers in your field

- rapid publication on acceptance

- support for research data, including large and complex data types

- gold Open Access which fosters wider collaboration and increased citations

- maximum visibility for your research: over $100 \mathrm{M}$ website views per year

At BMC, research is always in progress.

Learn more biomedcentral.com/submissions 